\title{
Penerapan Teknologi Epoxy Wooddan Pallet dari Limbah Kayu sebagai Produk Kerajinan Unik Bernilai Ekonomis Tinggi bagi Kelompok Pengrajin di Desa Sangkanayu, Kecamatan Mrebet Kabupaten Purbalingga
}

\section{Technological Applications of Epoxy Wood and Pallet Made from Wood Wastes as Unique and High Value Craft Products for a Group of Craftsmen in Sangkanayu Village, Mrebet Sub-district, Purbalingga Regency}

\author{
Bambang Sugiantoro' ${ }^{1)}$, Sakuri ${ }^{2)}$, Hartono ${ }^{3)}$ \\ ${ }^{1}$ Program Studi Teknik Mesin, ${ }^{2}$ Program Studi Teknik Industri, \\ ${ }^{3}$ Program Studi Teknik Elektro, \\ Sekolah Tinggi Teknik (STT) Wiworotomo, Purwokerto \\ biotech.machining@gmail.com, sakuri@yahoo.com, hartono.fahmi@gmail.com
}

\begin{abstract}
Abstrak
Purbalingga mempunyai keunggulan ketersediaan kayu yang tinggi, kondisi tanah yang kebanyakan pegunungan sangat mendukung tumbuhnya kayu keras, hampir setiap desa memiliki jumlah tanaman keras yang melimpah. Beberapa perusahaan kayu lapis dan mebelair juga banyak menginvestasikan dibidang produksi kayu lapis dan barecore di beberapa kawasan di purbalingga. UKM mebelair, kayu lapis dan kusen membutuhkan tenaga kerja yang cukup banyak, tidak membutuhkan pendidikan formal, sehingga terbuka pengentasan tenaga kerja secara umum. UKM pengrajin mebelair dan kusen kayu di Desa Sangkanayu, Kecamatan Mrebet, Kabupaten Purbalingga, membuat model berdasarkan pesanan lokal, tidak mengikuti trend furniture terbaru, memiliki kesulitan pada pembentukan model radius dan lengkung, finishing kurang halus dan waktu yang lama. Kayu dengan lubang dan tidak simetris biasanya tidak digunakan sebagai produk kusen/furnitur, limbah kayu dalam bentuk potongan secara umum tidak dimanfaatkan, padahal volume kayu limbah pada pembentukan mencapai kurang lebih 30\% dari bahan baku. UKM mebelair belum memiliki pengetahuan pembentukan kayu dari limbah untuk menjadi produk kerajinan. Disamping itu pengetahuan manajeman usaha, pengelolaan keuangan, dan metode pemasaran produk juga masih rendah hanya menunggu pelanggan, mengakibatkan UKM sulit berkembang, persaingan harga antar UKM. Permasalahan pembentukan dengan menggunakan limbah kayu dan bahan baku dalam bentuk potongan digunakan untuk pembuatan kerajinan. Pembentukan ditingkatkan dengan kemampuan untuk membentuk lengkung menggunakan cutting vertical/bendsaw, untuk percepatan pembelahan menggunakan mesin TTG circle cutting. Teknologi yang diterapkan untuk pemanfaatan limbah kayu akibat kerusakan lobang, tidak lurus, akan diubah menjadi produk bernilai ekonomis tinggi, unik dengan epoxy wood resin. Metode pembentukan produk kusen dan mebelair dari kayu (limbah) akan memberikan alternatif untuk meningkatkan nilai tambah dan pendapatan, keuntungan lainnya penggunaan epoxy juga meningkatkan daya tahan, anti rayap dan bernilai ekonomis tinggi, berpotensi memiliki brand merk yang khas. Untuk penguatan manajemen, UKM dikenalkan administrasi keuangan, dan strategi pemasaran produk secara online. Solusi diatas diharapkan akan meningkatkan daya saing dan produktifitas UKM, desain produk baru dengan memanfaatkan limbah kayu untuk menjadi produk dinding kayu, dan produk epoxy wood resin, akan meningkatkan pendapatan UKM.
\end{abstract}

Kata kunci: epoxy wood resin, wooden wall, circle rotary.

\section{Abstract}

Purbalingga has the advantage of high wood availability, the condition of the land that is mostly mountainous strongly supports the growth of hardwood, almost every village has an abundance of perennials. Several plywood and furniture companies also invested heavily in the production of plywood and barecore in several areas in Purbalingga. Furniture furniture, plywood and sills need a lot of workforce, do not need formal education, so there is a general elimination of labor. UKM of furniture and wood frame craftsmen in Sangkanayu Village, Mrebet Subdistrict, Purbalingga Regency, make a model based on local orders, do not 
follow the latest furniture trends, have difficulty in forming radius and curved models, less smooth finishing and long time. Holey and asymmetrical wood is usually not used as a frame / furniture product, wood waste in the form of pieces is generally not utilized, even though the volume of waste wood at the formation reaches approximately $30 \%$ of the raw material. Mebelair UKM has no knowledge of wood formation from waste to become handicraft products. Besides that, business management knowledge, financial management, and product marketing methods are also still low, just waiting for customers, which makes it difficult for SMEs to develop, price competition among SMEs. The problem of formation by using wood waste and raw materials in the form of pieces is used for making crafts. Formation is enbanced by the ability to form curves using vertical cutting/bendsaw, for acceleration of cleavage using circle cutting machine. The technology applied to the utilization of wood waste due to damage to the bole, not straight, will be converted into bigh economic value products, unique with epoxy wood resin. The method of forming frame and furniture products from wood (waste) will provide an alternative to increase added value and income, other benefits of using epoxy also increase durability, anti termites and high economic value, potentiallyhaving a distinctive brand brand. To strengthen management, SMEs are introduced to financial administration, and online product marketing strategies. The above solution is expected to improve the competitiveness and productivity of SMEs, the design of new products by utilizing wood waste to become wood wall products, and epoxy wood resin products, will increase the income of SMEs.

Keywords: epoxy wood resin, wooden wall, circle rotary.

\section{PENDAHULUAN}

Purbalingga mempunyai keunggulan kesediaan kayu yang tinggi, kondisi tanah yang kebanyakan pegunungan sangat mendukung tumbuhnya kayu keras, hampir setiap desa memiliki jumlah tanaman keras yang melimpah, luas hutan kayu mencapai 30.535,58 HA, BPS Jateng, (2016) Kerajinan dan pengolahan kayu merupakan salah satu dari tujuh produk unggulan purbalingga, data Pemkab Purbalingga, (2017). Beberapa perusahaan kayu lapis dan mebelair juga banyak menginvestasikan dibidang produksi kayu lapis dan barecore di beberapa kawasan di purbalingga. UKM mebelair, kayu lapis dan kusen membutuhkan tenaga kerja yang cukup banyak, tidak membutuhkan pendidikan formal, sehingga terbuka pengentasan tenaga kerja secara umum. Saat ini jumlah UKM kayu baik UKM dan perusahaan di seluruh kabupaten purbalingga mencapai seratus perusahaan menengah dan ribuan UKM, Data Ukm Center, Dinsosnakertrans Purbalingga (2016).

Desa Sangkanayu, Kecamatan Mrebet, Purbalingga, mempunyai luas total $221.525 \mathrm{Ha}$, dengan $193.125 \mathrm{Ha}$ adalah tanah kering dan hampir $70 \%$ untuk perkebunan kayu, sedangkan 28.400 ha, Tanah basah BPS.Kecamatan Mrebet, (2016), Pekerjaan penduduk $97 \%$ swasta, dari beberapa UKM di desa, terdapat 12 pengrajin mebelair dan kusen, data Desa
Sangkanayu (2017), delapan UKM dibidang kusen dan 4 UKM memproduksi furniture. UKM Mitra Sukses pimpinan Sukamto, wokshop di Rt $07 \mathrm{Rw}$ 03, dengan 4 karyawan tetap, yang lebih banyak membuat kusen kayu untuk rumah, omset 7,5-8 juta per minggu, (wawancara Sukamto, 2017). Dari omset tersebut rata rata keuntungan adalah $25 \%$, keuntungan kotor 1,5-2,0 juta/minggu, gaji pegawai dibayarkan per-akhir pekan sesuai target produksi. Rata rata perhari adalah 35-50 ribu, Dengan Rata-rata penghasilan perpekan sebesar 350-400 ribu/pegawai, keuntungan sangat minim karena habis untuk operasional. Perlu ada produk yang mampu menembus pangsa pasar menengah, sehingga harga dapat lebih tinggi. UKM Maju Jaya dalam membuat model lebih didasarkan pesanan untuk memenuhi kebutuhan lokal, memiliki permasalahan finishing kurang cepat dan halus, karena poles dan amplas masih manual. Proses finishing membutuhkan waktu yang lama, menghambat proses produksi, disamping itu limbah debu sangat mengganggu, ruang produksi penuh lapisan debu.

UKM secara umum belum memiliki pengetahuan manajeman usaha yang memadai, pengelolaan keuangan, dan metode pemasaran produk terbatas, yang mengakibatkan UKM tidak berkembang cepat. Untuk mendapatkan bahan baku 
UKM membeli sekaligus perpohon, yang digunakan adalah pada kayu yang lurus dan banyak kayu dalam ukuran pendek dan memiliki cacat terbuang.UKM rata-rata belum memanfaatkan limbah kayu dengan ukuran kecil menjadi produk bernilai ekonomis. UKM Mitra Sukses, untuk menjaga mutu kusen, maka kayu yang digunakan harus berkualitas baik, sehingga banyak bahan baku yang rusak sebagian tidak dapat digunakan untuk produk kusen dan diklasifikasikan menjadi limbah.

Pada proses produksi UKM menghasilkan banyak limbah yang belum dimanfaatkan. Limbah kayu dengan kerusakan akibat lobang, tidak lurus, terkena rayap, akan diubah menjadi produk bernilai ekonomis tinggi, unik dengan epoxy wood resin dan wooden wall. Metode ini paling tepat untuk merubah berbagai limbah untuk meningkatkan nilai tambah, keuntungan lainnya penggunaan epoxy juga meningkatkan daya tahan, anti rayap dan bernilai ekonomis tinggi, sangat strategis untuk meningkatkan UKM agar mampu memperluas pangsa pasar.

Dari survey dan identifikasi, permasalahan UKM dikelompokan menjadi 3; yaitu (1) Sistem produksi dan pemanfaatan limbah belum optimal, (2) Sistem manajemen organisasi yang masih sederhan, laporan keuangan, modal kecil, dan pembukuan yang tidak baik, (3) dan pemasaran yang lemah dan bersifat lokal.

\section{METODE}

\section{Solusi Yang Ditawarkan}

Berdasarkan klasifikasi dan identifikasi permasalahan skala prioritasyang dihadapi mitra UKM mebelair dan kusen kayu agar dapat berkembang, pada tabel 1 .

Tabel 1:

Permasalahan skala prioritas mitra dan solusi yang ditawarkan melalui PKM

\begin{tabular}{|c|c|c|}
\hline No & $\begin{array}{c}\text { Permasalahan skala prioritas } \\
\text { Mitra }\end{array}$ & Metode Pendekatan/solusi yang akan Ditawarkan \\
\hline 1 & $\begin{array}{l}\text { Alat yang digunakan untuk } \\
\text { finishing, (poles dan grinding masih } \\
\text { manual) kotor, banyak limbah debu, } \\
\text { dan lama }\end{array}$ & $\begin{array}{l}\text { Membuat alat poles untuk mempercepat finishing dengan } \\
\text { mempercepat poles dan finishing dengan membuat poles } \\
\text { portable dengan penghisap debu otomatis, sehingga poles } \\
\text { dapat lebih cepat dengan luas permukaan yang lebih besar }\end{array}$ \\
\hline 2 & $\begin{array}{l}\text { Banyak kayu limbah, dan kayu } \\
\text { dengan cacat ringan dan potongan } \\
\text { tidak dimanfaatkan }\end{array}$ & $\begin{array}{l}\text { Melatih membuat Memanfaatkan limbah kayu dengan } \\
\text { kerusakan akibat lobang, tidak lurus, terkena rayap, akan } \\
\text { diubah menjadi produk bernilai ekonomis tinggi, unik } \\
\text { dengan epoxy wood resin. berpotensi menjadi brand produk } \\
\text { yang khasdiberi merk dagang menggunakan sablon plastik. }\end{array}$ \\
\hline 3 & $\begin{array}{l}\text { Belum memiliki pemotong yang } \\
\text { cepat untuk pembentukan model } \\
\text { kayu }\end{array}$ & $\begin{array}{l}\text { Membuat pemotong yang cepat untuk pembentukan } \\
\text { model epoxy wood, dengan circle cutting berpengatur } \\
\text { putaran, yang akan mempercepat pemotongan limbah kayu } \\
\text { untuk model panel wood, yang efisien dengan rangka kayu }\end{array}$ \\
\hline 4 & $\begin{array}{l}\text { Pengetahuan UKM pada } \\
\text { permasalahan manajeman usaha, } \\
\text { keuangan, dan metode pemasaran } \\
\text { produk rendah mengakibatkan } \\
\text { UKM sulit berkembang dan produk } \\
\text { masih belum dipasarkan secara luas }\end{array}$ & $\begin{array}{l}\text { a. Memberikan pelatihan dan diklat singkat } \\
\text { kewirausahaan } \\
\text { b. Pelatihan pembukuan keuangan, akutansi sederhana } \\
\text { pada UKM untuk menghitung cash flow dan } \\
\text { keuntungan per bulan } \\
\text { c. Ceramah dan pelatihan strategi pemasaran secara } \\
\text { online (penjualan produk online). } \\
\text { d. Penyuluhan perkembangan usaha dengan pelatihan } \\
\text { dan studi banding ke UKM yang sudah sukses. }\end{array}$ \\
\hline
\end{tabular}


Sedangkan untuk produk hasil terdiri dari wall wood panels, epoxy dan handy craft. Jenis poduk dan aplikasinya untuk kebutuhan rumah medium.

\section{Teknologi tepat guna yang diaplikasikan}

1. Mesin bensaw pembentuk profil

Gambar 1:

TTG bendsaw berpengatur putaran dengan rangka kayu dan besi

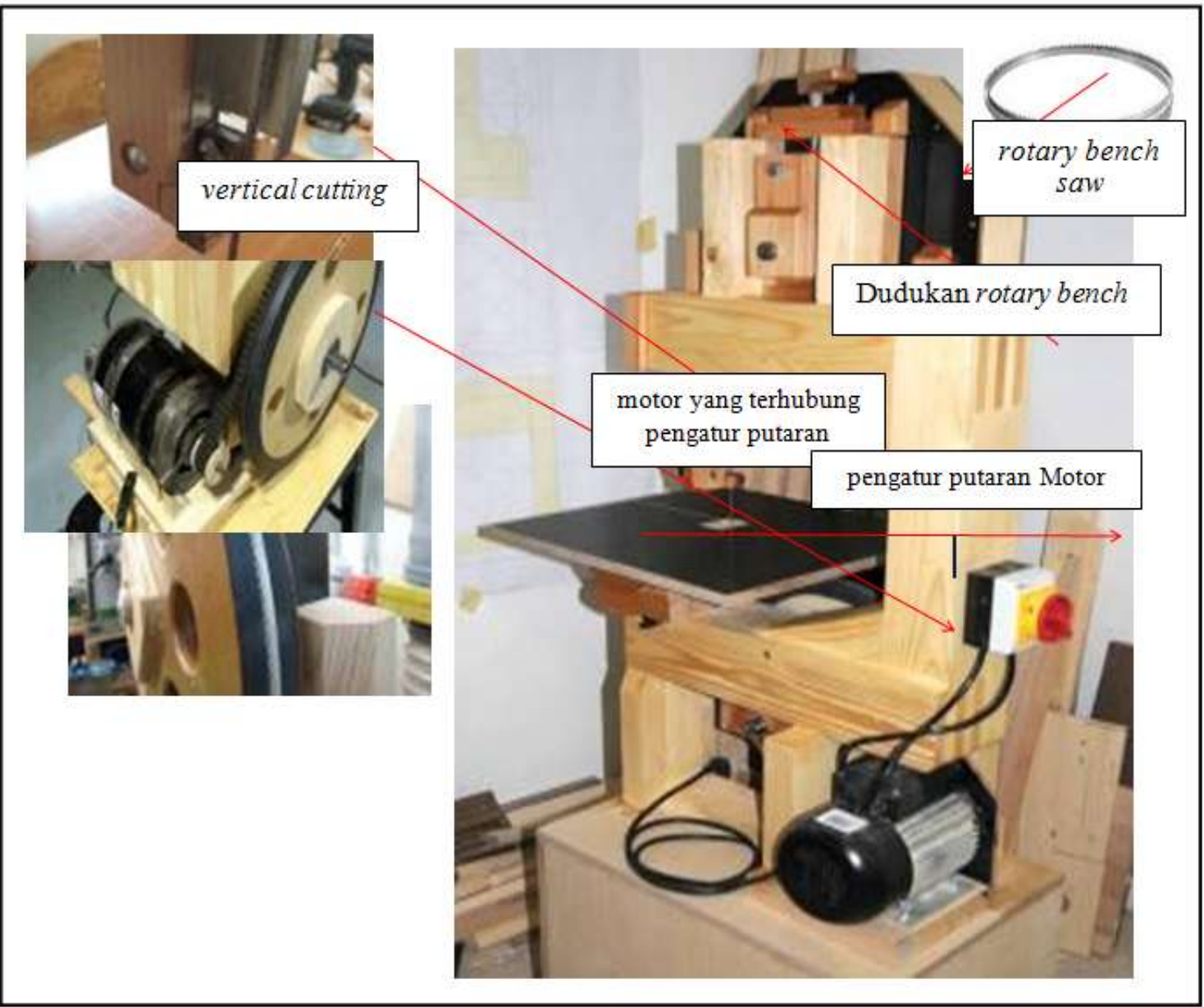

Spesifikasi :

a. Dimensi meja potong rotary / vertical cutting P x L x T: $85 \times 75 \times 145 \mathrm{~cm}$.

b. Meja dan rangka dibuat dari kayu mahoni dengan ketebalan variasi 5 $\mathrm{cm}, 10 \mathrm{~cm}$ dan $20 \mathrm{~cm}$, pemotongan menggunakan gergaii tangan.

c. Tinggi kaki meja $95 \mathrm{~cm}$, agar ergonomis sesuai fungsi dan tidak menyebabkan kelelahan operator.

d. Rotary bench saw menggunakan ukuran yang dapat diatur dari lebar $0,75,1$, dan 1,5 inch, sesuai beban potong dan berdasarkan ketelitian, e. Meja disambung menggunakan paku dan lem kayu sehingga sambungan lebih kuat dan kokoh.

f. Pengaturan rotary disesuaikan dengan panjang pisau yang akan digunakan, diameter dudukan menggunakan karet untuk mencegah terjadinya slip pada saat proses pembentukan dan pemotongan, diameter sisi pengatur $60 \mathrm{~cm}$.

g. Rangka dicat dan di lapis dengan cat semprot untuk ketahanan terhadap rayap 
Gambar 2:

Pelatihan penggunaan TTG bendsaw cutting
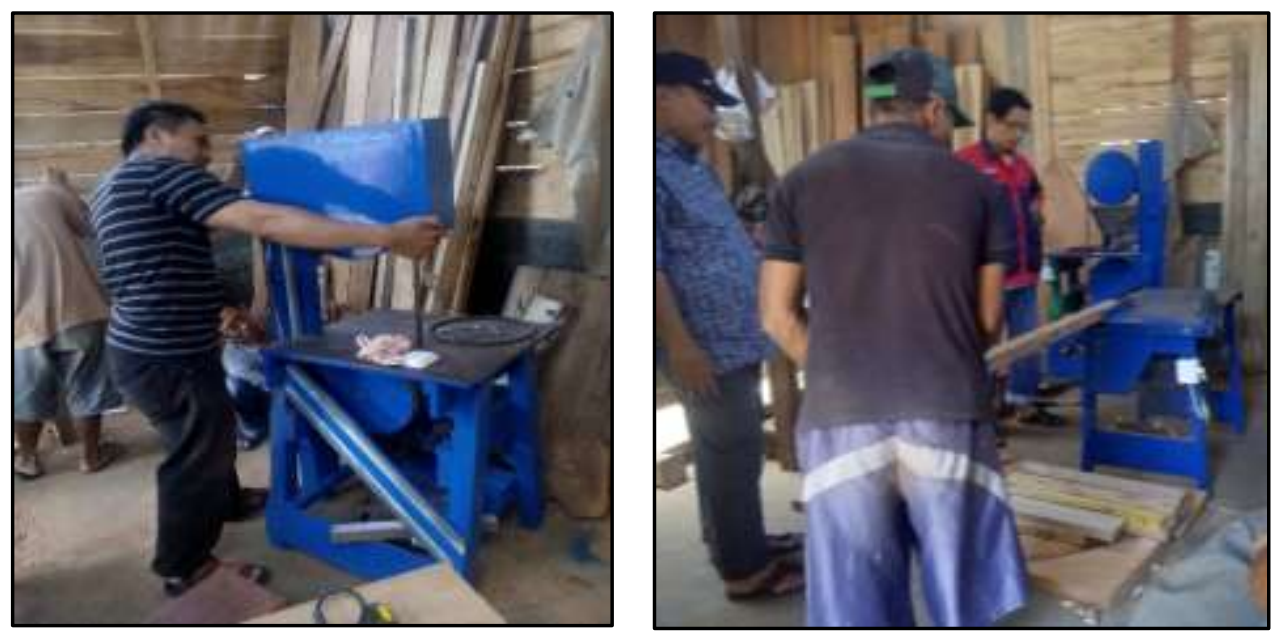

\section{a. Teknologi Tepat Guna Mesin} Cirle Cutting

Gambar 3:

TTG circle cutting
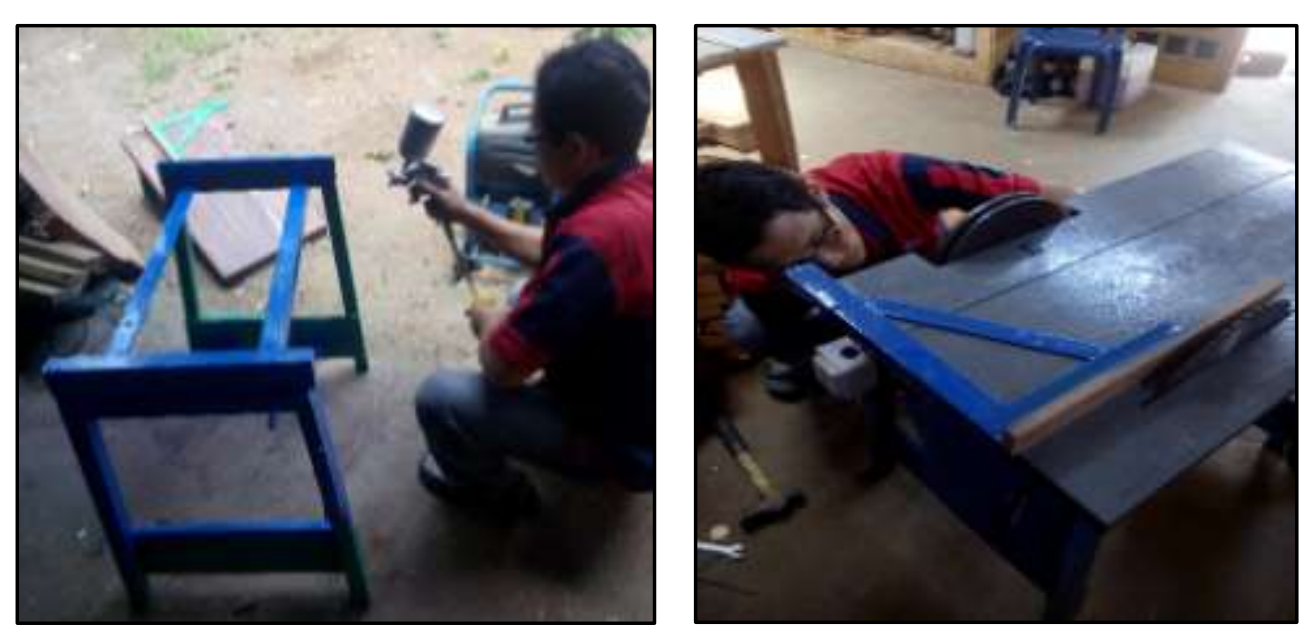

Spesifikasi :

a. Dimensi circle machinedengan panjang bebas, lebar $100 \mathrm{~cm}$ lebar $70 \mathrm{~cm}$, tinggi $70 \mathrm{~cm}$

b. Kerangka besi plat dan siku 80 x 60 x 60 ketebalan 1,5 mm. Kaki-kaki bollow $3 \times 4 \mathrm{~cm}$, penyambungan kerangka sebagian menggunakan las listrik SMAW dan diperkuat dengan baud.

c. Motor penggerak rotary menggunakan motor daya $1 \mathrm{PK}$. d. Rangka di cat dan di lapis clear agar tahan lama, pelapisan dilakukan dengan metode spray.

Teknologi tepat guna yang diaplikasikan

\section{Teknik Epoxy Wood dan Wooden Wall}

Bahan baku, berupa kayu dengan kondisi umum, dapat berupa katu cacat, dan limbah, Kayu yang akan diepoxy dibersihkan, buang bagian yang kropos, dibentuk sesuai model mebelair yang 
diinginkan.Untuk membuat sisi yang halus dan simetris, semua bahan baku di samakan modelnya, akan lebih maksimal di poles, sehingga tidak ada debu dan kotoran lain yang menempel. Bahan dibersihkan dengan udara compressor untuk meyakinkan bahwa tidak ada debu di permukaan kayu , bentuk secara simetris, Kayu yang sudah dibentuk disatukan dengan lem kayu sesuai dimensi yang akan dibuat, kemudian ditahan dengan planner jepit sampai ikatan lem kuat, kemudian dikedua sisi masing asing kayu diberi akrilik.Kayu yang sudah dibersihkan dan dimensi sudah diukur secara teliti disusun dan di asemlbing sesuai dengan luas yang ingin dibuat, Membuat cetakan, dengan akrilik bening dengan tebal $1 \mathrm{~mm}$, di bentuk sesuai bidang yang akan dibentuk, Perkuat cetakan dengan penahan untuk menjaga akurasi dan tidak terjadi pergeseran,Mencampur epoxy resin bening dengan hardener dengan perbandingan 1 $\mathrm{kg}$ hardener dapat digunakan untuk 1:201:40,Durcon Incorporated (2010), Pile, John F,(2006).

Lubang kayu dan permukaan yang mempunyai cacat lubang diisi dengan resin, dan atur kerataannya dengan menggunakan kuas,tahapan teknis dapat dilihat gambar 4.

Gambar 4:

Tahapan pembentukan epoxy wood

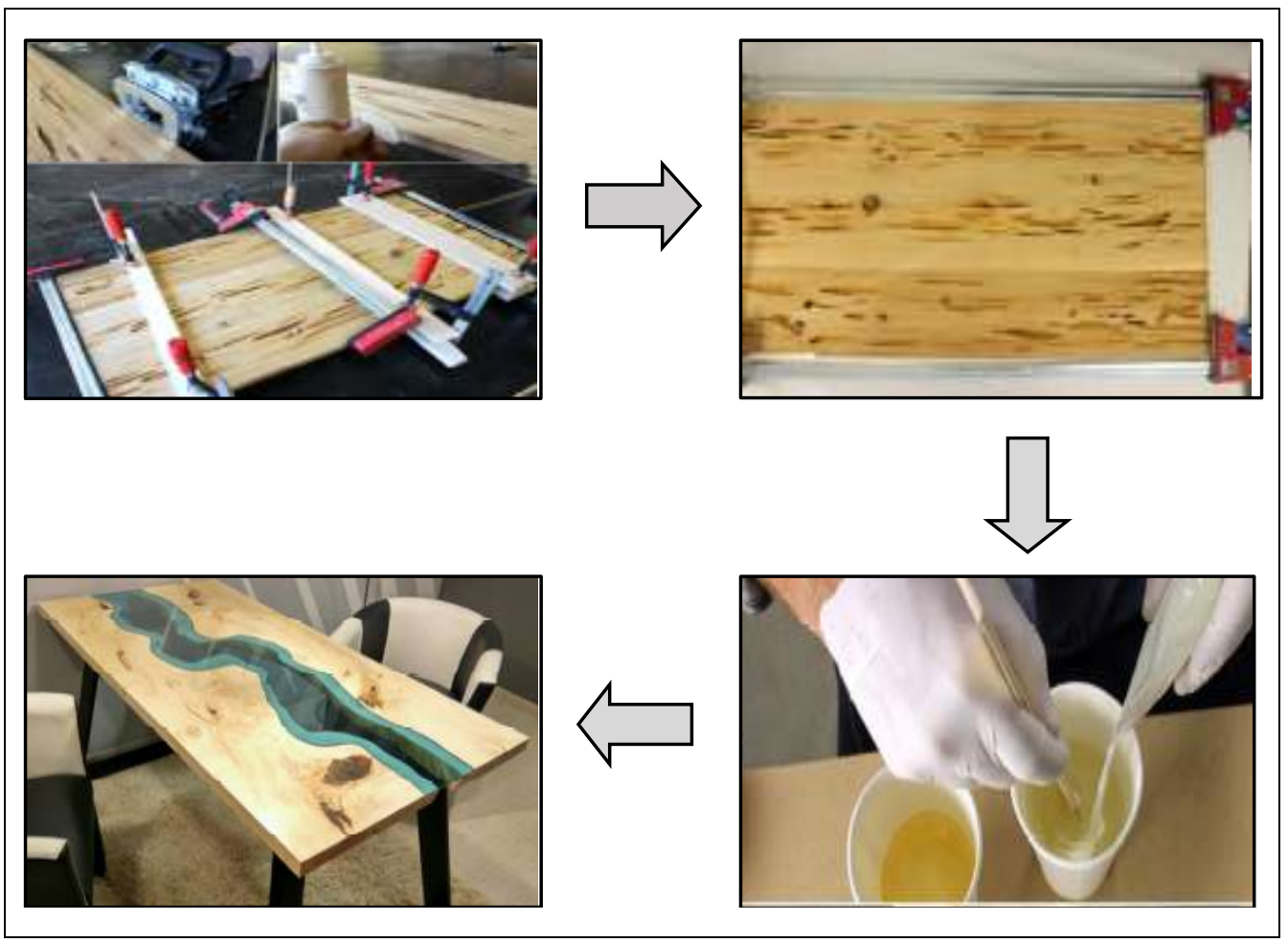

Langkah pembuatan wall wood panels dari limbah kayu

1. Kayu limbah dikumpulkan diutamakan yang berasal dari kayu yang keras, dikelompokan sesuai ukuran dan tektur waran,

2. Kayu limbah di potong sesuai dengan model wall panels wood yang akan dibuat, untuk desain $3 \mathrm{D}$, kontur kayu dibuat dengan ketebalan yang berbeda beda

3. Bentuk papan yang akan digunakan untuk model dinding kayu, cari kayu yang tahan rayap dan kuat, berilah dudukan untuk posisi penenpatan di dinding, 
4. Untuk kualitas yang baik, kayu di lapis dengan pernis, agar tektur semakin jelas dan bersih,tahapan pembentukan seperti pada gambar 5

Gambar 5:

Tahapan pembuatan wall panels wood dari limbah kayu bernilai tinggi
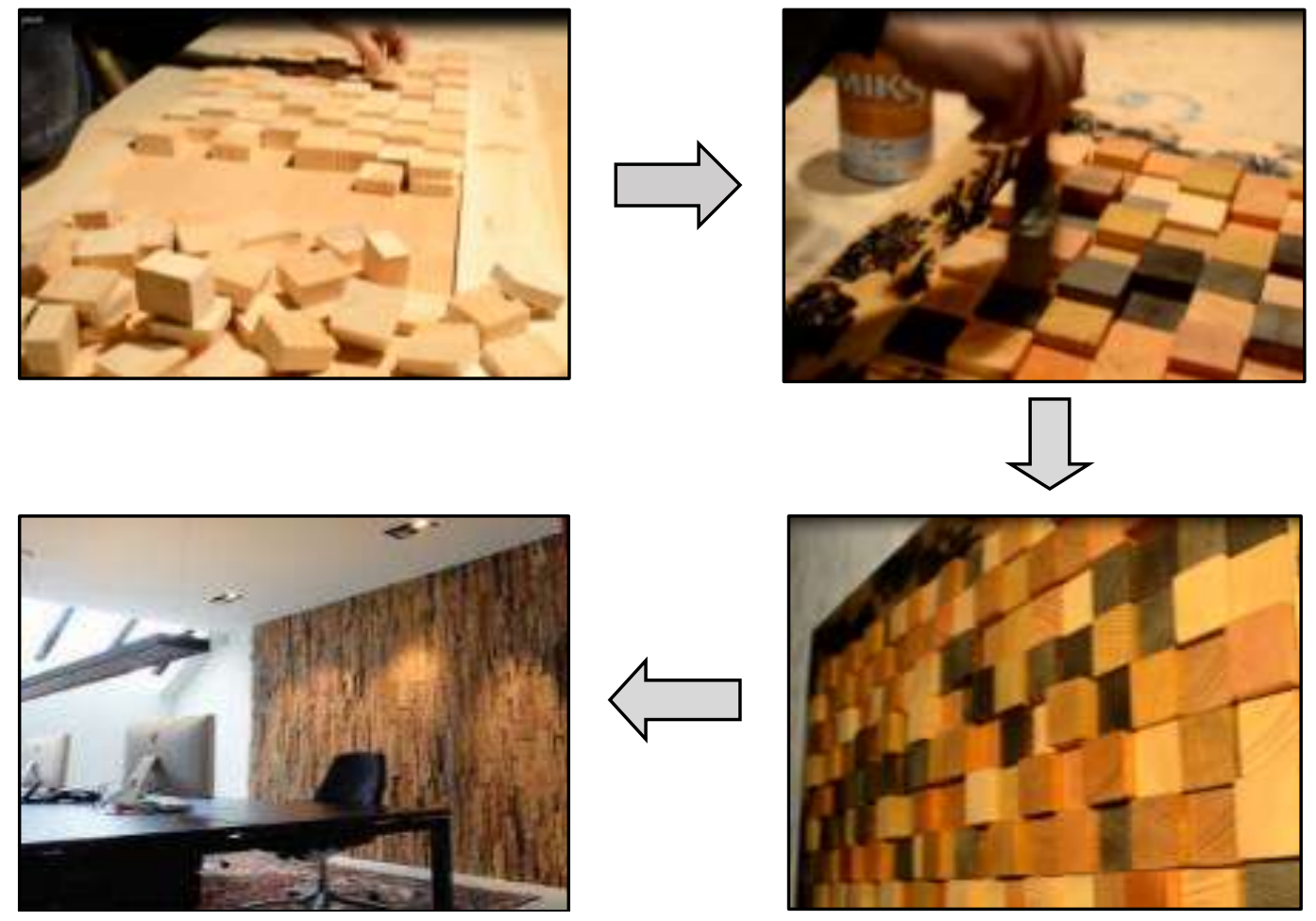

Pemilihan

bentuk

dan pengelompokan berdasarkan model wooden wall disusun sesuai desain, kayu potongan di lem sesuai dengan posisi desain, posisi dan pemilihan warna yang tepat sangat dibutuhkan untuk hasil optimal, agar muncul gradasi dan efek 3 D. Berikutnya kayu dilapis dengan pernis untuk membuat tekstur warna lebih jelas. Pengetahuan dan metode epoxy perlu dijelaskan pada tukang secara detail untuk menghindari kesalahan dalam proses epoxy. Pelatihan teori epoxy, penggunaan TTG, ergonomi dijelaskan pada tukang, ditunjukkan gambar 6 .
Gambar 6:

Pelatihan teori dan teknologi epoxy dan pallet
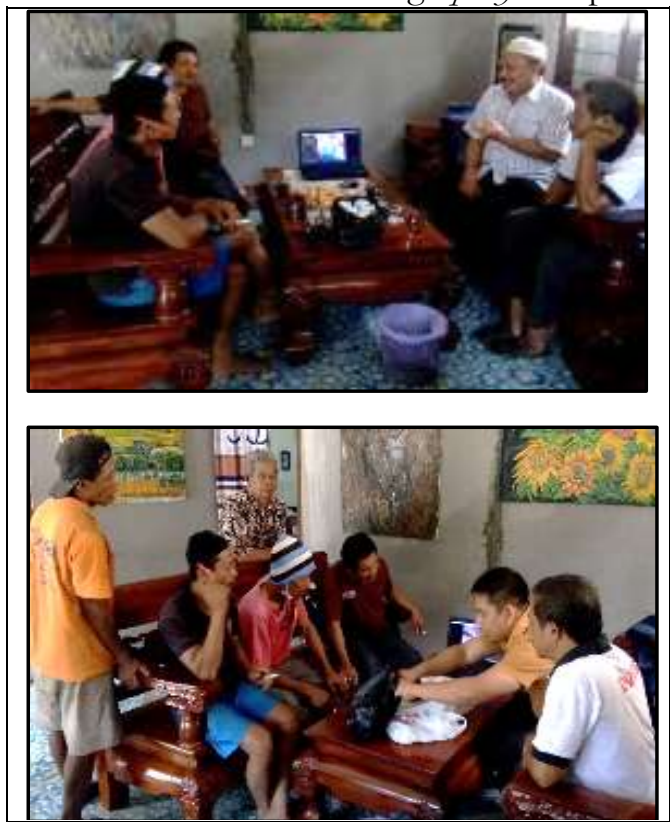
Pelatihan desain produk untuk pembuatan model unik dan untuk kebutuhan handycraft, bahan baku yang akan digunakan adalah kayu dengan kekerasan yang baik dan terutama adalah warna asli dengan serat kayu yang indah, pada pelatihan pertama digunakan kayu mahoni dari tunggak kayu yang dibelah untuk mendapatkan bahan dasar yang memadai untuk produk epoxy, Pada tahapan selanjutnya adalah proses pemodelan dan pembuatan cetakan epoxy dengan menggunakan kayu yang dibentuk sesuai dengan ukuran meja secara umum.

Mutu pelapisan kayu disesuaikan fungsinya untuk meningkatkan ketahanan dan usia kayu, Sutomo,(2001), seperti ditunjukan gambar 7 .

\section{Gambar 7:}

Penentuan dimensi dan model produk untuk mendapatkan bentuk unik
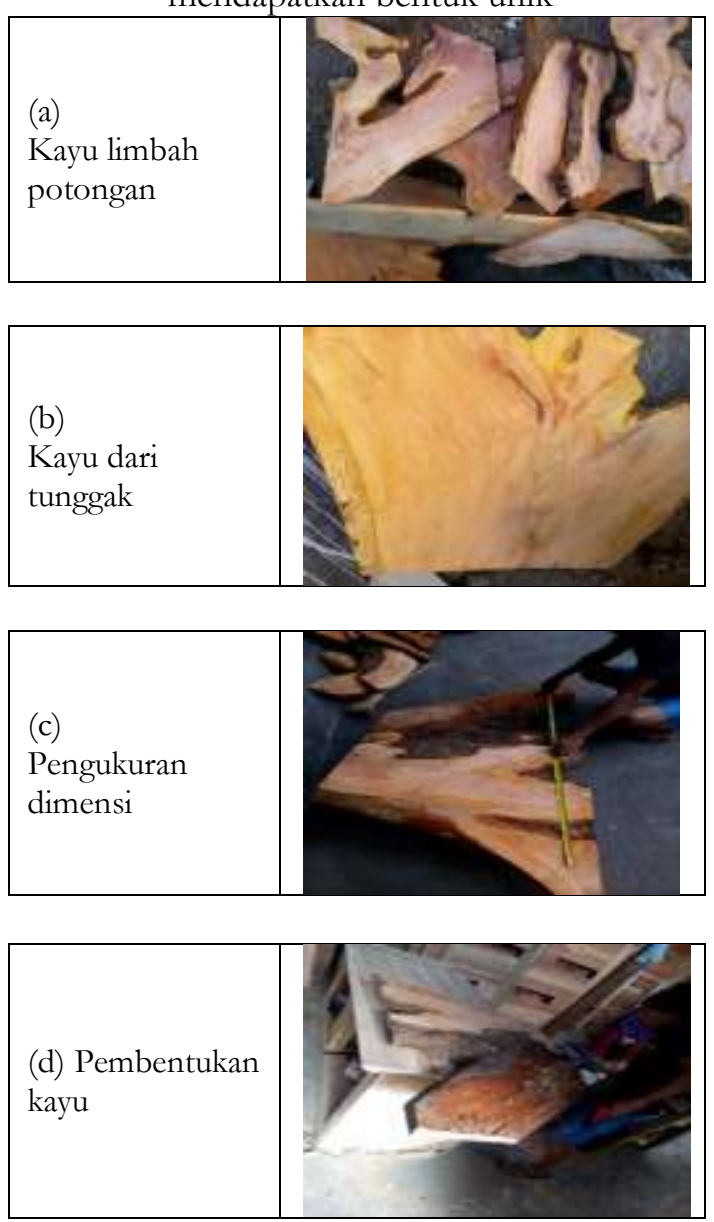

Produk epoxy yang akan dibuat dilakukan dengan memanfaatkan limbah kayu dengan kerusakan akibat lobang, tidak lurus, terkena rayap, akan diubah menjadi produk bernilai ekonomis tinggi, unik dengan epoxy wood resin. Metode epoxy dan wooden wall merupakan metode baru untuk minimalisasi limbah, berpotensi menjadi brand produk yang khas. Untuk pembentukan kayu dibuat mesin T'TG untuk membuat pemotong yang cepat untuk pembentukan model radius untuk profil kusen, dan bahan bakuepoxy wood, dengan circle cutting berpengatur putaran, yang akan mempercepat pemotongan limbah kayu untuk model panel wood dan tahapan pembuatannya dengan menggunakan media video agar mudah dipahami oleh tukang kayu.

\section{Solusi untuk mengatasi permasalahan di bidang mutu produk dan manajemen \\ Penguatan manajemen UKM} dilakukan dengan pelatihan administrasi keuangan, dan prinsip keselamatan dan kesehatan kerja (K3). Pengolahan kayu terutama pada proses pembelahan dan penghalusan (poleshing) menghasilkan debu halus yang berbahaya bagi kesehatan, untuk menghindari efek jangka panjang operator dan tukang kayu diarahkan untuk secara dispiplin menggunakan masker. Pada tinjauan ergonomi, pada saat bekerja posisi badan berpengaruh terhadap terjadinya cidera, untuk menghindari hal tersebut tukang dibekali prinsip ergonomi dalam bekerja, Tarwaka,(2014). Mutu produk pada pengolahan sangat berpengaruh pada penetrasi pasar kerajinan kayu, Soetomo, (2001), berpotensi meningkatkan ekonomi lokal, Rahma, Hania (2012).

Khusus untuk modal usaha, dengan Memberi wawasan penggunaan modal melalui KUR sehingga mampu meningkatkan omset tanpa bergantung pada buyer langsung. Mengundang pihak terkait untuk menambah kepercayaan 
perbankkan kepada UKM, untuk dapat mengakses kredit bunga rendah sesuai kebijakan pemerintah.

\section{KESIMPULAN DAN SARAN}

\section{Kesimpulan}

1. Penggunaan mesin bend saw mampu membentuk profil dan pembentukan kayu secara mudah sehingga produk dapat lebih cepat diselesaikan dibandingkan dengan dilakukan secara manual, reduksi waktu proses mencapai $50 \%$.

2. Kekuatan ikatan dipengaruhi rasio pencampuran, untuk mendapatkan sifat ikatan yang baik dan ulet dibutuhkan Perbandingan resin dan hardener yang tepat yaitu 1: 30 .

3. Pelatihan manajemen usaha, strategi pemasaran, dan pengetahuan mengakses modal usaha membuka wawasan baru dan memotivasi perkembangan usaha, meningkatkan produktifitas dan pendapatan kelompok.

\section{Saran}

1. UKM masih harus mau membuat produk alternatif berupa kerajinan kayu terutama dari kayu limbah sehingga akan meningkatkan nilai ekonomi.

2. Perlu dikembangkan model promosi produk dengan tampilan yang lebih menarik secara online agar mampu mendapat perhatian konsumen.

\section{UCAPAN TERIMA KASIH}

Penulis mengucapkan terima kasih kepada Kementerian Riset Teknologi Dan PendidikanTinggi (Kemenristekdikti) Republik Indonesia yang telah memberikan dana untuk Pengabmas Program PKM Tahun Anggaran 2017-2018.

\section{DAFTAR PUSTAKA}

BPS Jateng. (2016). Potensi Hutan Kayu di Purbalingga. Provinsi Jawa Tengah dalam Angka.

BPS Desa Sangkanayu. (2016).
BPS Statistik Daerah Kecamatan Mrebet. (2016)

Durcon Incorporated. (2010). Epoxy Resin Handbook. USA

Pemerintah kabupaten Purbalingga. (2016). Profil UKM Purbalingga. Dinsosnakertrans Purbalingga.

Pemerintah Kabupaten Purbalingga. (2017). Tujuh Produk Unggulan Purbalingga

Pile, J. F. (2007). Interior Design (Third Edit). New York.

Rahma, H. (2012), Buku Acuan Penerapan Pengembangan Ekonomi Lokal untuk Kota dan Kabupaten. Jakarta: Direktorat Jenderal Cipta Karya Kementerian Pekerjaan Umum.

Soetomo. (2001). Industri Pengolahan Kayu. Jakarta: Majalah kehutanan Indonesia.

Tarwaka. (2014). Dasar-Dasar Pengetahuan Ergonomi dan Aplikasi di Tempat Kerja. Jakarta: Harapan Press. 